\title{
KAJIAN UJI KUAT LEKAT BAJA PADA BETON HIGH VOLUME FLY ASH MEMADAT SENDIRI DAN BETON NORMAL
}

\author{
Karin Sebastia Lintang ${ }^{1}$, Agus Setiya Budi ${ }^{2)}$, Senot Sangadji ${ }^{3)}$ \\ 1) Mahasiswa Program Studi Teknik Sipil Fakultas Teknik Universitas Sebelas Maret \\ 2) 3) Dosen Program Studi Teknik Sipil Fakultas Teknik Universitas Sebelas Maret \\ Jl. Ir. Sutami 36 A, Kentingan Surakarta 57126, Telp (0271) 647069, Fax 662118 \\ Email : karinsebastia@student.uns.ac.id
}

\begin{abstract}
Fly ash comes from residual coal combustion ash which contains $80 \%$ chemical properties of silica and alumina. Silica compounds contained in the fly ash will eliminate the presence of $\mathrm{Ca}(\mathrm{OH})_{2}$ in the mortar which is disadventageous and reduce the compressive strength by reacting to form CSH or tubermorite which is the main compound that builds concrete's strength. The concept of using fly ash which often used in large quantities (3565\%) as a cement subtituent known as High Volume Fly Ash Concrete (HVFAC). The use of the HVFAC concept is combined with Self Compacting Concrete (SCC) to overcome pore's forming problem in reinforced concrete. This study examines the bond strength of HV FA-SCC and normal concrete. The research method for this study is the experiment using 2 variations of fly ash levels in HVFA-SCC concrete, namely 50\%, $60 \%$, and normal concrete used as a comparison. Each variation consists of 3 cube samples measuring $150 \mathrm{~mm} \times 150 \mathrm{~mm} \times 150 \mathrm{~mm}$. The quality for the sample is uniform, which is $30 \mathrm{MPa}$. The results obtained from the testing of existing samples are HVFA-SCC concrete load-displacement relationship curves compared to normal concrete aged 28 days. The results that can be obtained from the load-displacement relationship curve are the magnitude of the maximum pull force, displacement when maximum pull force occurs and it can be used to analyze the bond strength of HVFASCC concrete samples and normal concrete. Based on the results of the research that has been done, it can be concluded that the bond strength of HVFA-SCC concrete with 50\% fly ash content is 328,22\% greater than that of the normal concrete and the bond strength of HV FA-SCC concrete with $60 \%$ fly ash content is $218,84 \%$ greater than that of the normal concrete. The type of collapse that occurs in the testing of HVFASCC and normal concrete samples with pull out test is pull out failure.
\end{abstract}

Keywords : bond strength, fly ash, HVFA-SCC

\begin{abstract}
Abstrak
Fly ash berasal dari abu sisa pembakaran batu bara yang mengandung sifat kimia berupa silika dan alumina mencapai $80 \%$. Senyawa silika yang terdapat di dalam fly ash akan mengeliminir keberadaan $\mathrm{Ca}(\mathrm{OH})_{2}$ di dalam mortar yang sifatnya merugikan dan menurunkan kuat tekan dengan cara bereaksi membentuk CSH atau tubermorite yang membangun kekuatan beton. Konsep penggunaan fly ash yang sering digunakan dalam jumlah besar (35-65\%) sebagai subtituen semen dikenal dengan High Volume Fly Ash Concrete (HVFAC). Penggunaan konsep HVFAC dipadukan dengan Self Compacting Concrete (SCC) untuk mengatasi permasalahan terbentuknya rongga pada beton bertulang. Penelitian ini mengkaji kuat lekat pada beton HVFASCC dan beton normal. Metode penelitian ini ialah eksperimen menggunakan 2 variasi kadar fly ash pada beton HVFA-SCC yaitu 50\%,60\%, serta beton normal yang digunakan sebagai pembanding. Tiap variasi terdiri dari 3 sampel kubus berukuran $150 \mathrm{~mm}$ x $150 \mathrm{~mm}$ x $150 \mathrm{~mm}$. Mutu untuk sampel tersebut diseragamkan yaitu $30 \mathrm{MPa}$. Hasil yg didapatkan dari pengujian sampel yang ada berupa kurva hubungan load-displacement beton HVFA-SCC yang dibandingkan dengan beton normal usia 28 hari. Hasil yang didapatkan dari hubungan load-displacement adalah besarnya gaya cabut maksimal, displacement saat terjadi gaya cabut maksimal serta dipergunakan untuk menganalisis kuat lekat dari sampel beton HVFA-SCC dan beton normal. Berdasarkan hasil penelitian yang telah dilakukan diperoleh kesimpulan bahwa kuat lekat pada beton HVFA-SCC dengan kadar fly ash 50\% lebih besar 328,22 \% dibandingkan dengan kuat lekat pada pada beton normal dan pada beton HVFA-SCC dengan kadar fly ash 60\% kuat lekat lebih besar 218,84\% dibandingkan dengan kuat lekat pada pada beton normal. Tipe keruntuhan yang terjadi pada pengujian sampel HVFA-SCC maupun beton normal dengan pada pengujian pull out ialah pull out failure.
\end{abstract}

Kata Kunci : kuat lekat, fly ash, HVFA-SCC

\section{PENDAHULUAN}

Beton menjadi salah satu dari material yang banyak dimanfaatkan di dalam dunia konstruksi sebagai kebutuhan utama dari sebuah bangunan. Perkembangan ilmu pengetahuan terkait metode pelaksanaan konstruksi yang semakin pesat memberikan dampak positif bagi perbaikan produktivitas industri konstruksi dan pembangunan berkelanjutan di Indonesia.

Menurut Campion Josh 2000, "SelfCompacting Concrete (SCC) adalah campuran beton yang mempunyai karakteristik dapat memadat dengan sendirinya tanpa menggunakan alat pemadat (vibrator). Salah satu keunggulan dari Self Compacting Concrete (SCC) adalah dapat memadat ke setiap sudut dari struktur bangunan dan dapat mengisi tinggi 
permukaan yang diinginkan dengan rata (self leveling) tanpa mengalami bleeding dan segregasi (pisahnya campuran pasta dengan agregat) sehingga dapat meminimalisir air yang ada dalam campuran beton”.

Dilihat dari segi material yang digunakan, proporsi semen yang dibutuhkan dalam campuran SCC lebih banyak dibandingkan dengan beton normal, sehingga mendorong meningkatnya produksi semen Portland yang berkontribusi terhadap timbulnya efek rumah kaca (green house effect) dan memicu terjadinya pemanasan global (global warming), mengingat proses produksi satu ton semen menghasilkan $\mathrm{CO}_{2}$ setara dengan 0,55 ton dan memerlukan bahan bakar carbon yang akan pula menghasilkan emisi $\mathrm{CO}_{2}$ sebanyak 0,45 ton (Davidovits, 1994).

Salah satu cara untuk mencegah dampak polusi yang ditimbulkan akibat penggunaan semen dalam skala besar ialah dengan membuat suatu campuran yang ramah lingkungan dengan inovasi mengganti penggunaan material semen dengan material lain. Menurut beberapa penelitian yang telah dilakukan material yang umum digunakan sebagai pengganti semen adalah abu terbang (fly ash). Dalam beberapa penelitian, fly ash digunakan sebagai substituen semen dengan kadar yang cukup besar $(>50 \%)$ dari berat semen. Konsep tersebut dikenal dengan High Volume Fy Ash Concrete (HVFAC). Penelitian ini yang mengkaji nilai kuat lekat pada beton HVFA-SCC usia 28 hari dengan penggunaaan variasi kadar fly ash 50\% dan $60 \%$ dari berat semen yang kemudian dibandingkan dengan beton normal.

\section{DASAR TEORI}

\section{Reaksi Kimia}

Gel kalsium silikat hidrat yang sering disingkat C-S-H, memiliki komposisi yang bervariasi berbentuk rongga sebanyak $70 \%$ dari semen. Kalsium hidroksida yang dihasilkan akan membuat sifat basa kuat $(\mathrm{pH}=12,5)$. Ini menyebabkan semen sensitif terhadap asam (Galang, 2017). Hal ini karena $\mathrm{Ca}(\mathrm{OH})_{2}$ dalam beton mudah sekali bereaksi dengan asam membentuk garam yang berdampak pada pengeroposan beton.

Penambahan fly ash yang mengandung senyawa silika $\left(\mathrm{SiO}_{2}\right)$ akan mengeliminir $\mathrm{Ca}(\mathrm{OH})_{2}$. Keberadaan $\mathrm{Ca}(\mathrm{OH})_{2}$ di dalam mortar/beton akan bersifat merugikan dan menurunkan kuat tekan. $\mathrm{SiO} 2$ bereaksi dengan $\mathrm{Ca}(\mathrm{OH})_{2}$ membentuk $\mathrm{CSH}\left(3 \mathrm{CaO} \cdot \mathrm{SiO}_{2} \cdot 3 \mathrm{H}_{2} \mathrm{O}\right)$. Reaksi tersebut tersebar merata pada seluruh tempat di dalam beton termasuk pada ruang-ruang kosong pada lapisan agregat-pasta semen, sehingga menambah kekuatan lekatan antara agregat-pasta semen. Hal ini akan menambah kuat tekan beton, tetapi reaksi antara silica dengan kapur berlangsung sangat lambat, sehingga diperlukan waktu umur yang cukup lama untuk mencapai hasil kuat tekan yang optimal.

\section{Kuat Lekat Beton}

Gaya lekat pada suatu struktur beton bertulang ialah gaya geser longitudinal setiap satuan panjang tulangan yang terjadi pada permukaan tulangan yang bersinggungan dengan beton di sekelilingnya. Tegangan lekat juga dapat didefinisikan sebagai gaya lekat setiap satuan luas permukaan tulangan (Elagroudy, 2003).

Berdasarkan pull-out tests RILEM-CEB RC6 (1983), pengujian kuat lekat terhadap beton bertulang baja dihitung dengan rumus di persamaan 1 dan 2 .

$$
\begin{aligned}
& \text { Keterangan : } \\
& \mathrm{P} \quad=\text { Beban } \\
& \begin{array}{lll}
\mathrm{L} & =\text { Panjang Penyaluran }(\mathrm{mm}) \\
\varnothing & =\text { Diameter Baja } & (\mathrm{mm}) \\
\tau & =\text { Tegangan Lekat } & (\mathrm{Mpa})
\end{array}
\end{aligned}
$$

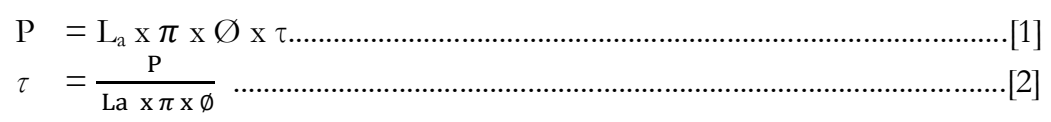

\section{METODE PENELITIAN}

Metode penelitian yang digunakan pada penelitian ini ialah metode eksperimental untuk mengkaji kuat lekat yang dilakukan di Laboratorium Bahan, Laboratorium Struktur, dan Laboratorium Teknik Mesin Fakultas Teknik Universitas Sebelas Maret. Pengujian kuat lekat dilakukan terhadap beton berumur 28 hari dengan bentuk berupa kubus berdimensi $150 \mathrm{~mm} \times 150 \mathrm{~mm} \times 150 \mathrm{~mm}$ dengan menggunakan variasi kadar fly ash $50 \%$ dan $60 \%$ serta beton normal. Tiap variasi terdiri dari 3 sampel. Selanjutnya data hasil pengujian tersebut akan diolah menggunakan Microsoft Excel. 
Tabel 1. Nama dan Jumlah Benda Uji

\begin{tabular}{|c|c|c|c|}
\hline $\begin{array}{c}\text { Kadar Fly } \\
\text { Ash }\end{array}$ & $\begin{array}{c}\text { Nama } \\
\text { Benda Uji }\end{array}$ & $\begin{array}{l}\text { Umur } \\
\text { (hari) }\end{array}$ & Jumlah \\
\hline \multicolumn{4}{|c|}{ Kuat Tarik Langsung } \\
\hline $50 \%$ & $\begin{array}{c}\text { KL-HVFA-SCC } \\
50 \%\end{array}$ & 28 & 3 \\
\hline $60 \%$ & $\begin{array}{c}\text { KL-HVFA-SCC } \\
60 \%\end{array}$ & 28 & 3 \\
\hline $0 \%$ (Normal) & & 28 & 3 \\
\hline \multicolumn{3}{|c|}{ TOTAL BENDA UJI } & 9 \\
\hline
\end{tabular}

\section{HASIL DAN PEMBAHASAN}

Pengujian agregat dilakukan di Laboratorium Bahan dan Struktur Universitas Sebelas Maret. Pada agregat halus pengujian yang dilakukan adalah kandungan lumpur dalam pasir, kandungan zat organik dalam pasir, spesific gravity agregat halus (SNI 1970 2008). Pada agregat kasar pengujian yang dilakukan adalah spesific gravity agregat kasar (SNI1969-2008), abrasi agregat kasar (SNI-2417-2008). Sedangkan material fly ash dilakukan pengujian XRF (X-Ray Fluorescence) di Laboratorium MIPA Terpadu Universitas Sebelas Maret. Hasil pengujian masing-masing material dapat dilihat sebagai berikut :

Tabel 2. Hasil Pengujian Agregat Kasar

\begin{tabular}{lccc}
\hline $\begin{array}{c}\text { Jenis Pen- } \\
\text { gujian }\end{array}$ & Hasil Pengujian & Standar & Kesimpulan \\
\hline $\begin{array}{l}\text { Absorbtion } \\
\text { Appearent Spe- } \\
\text { cific Gravity }\end{array}$ & $2,6478 \mathrm{gr} / \mathrm{cm}^{3}$ & - & - \\
\hline $\begin{array}{l}\text { Bulk Specific } \\
\text { Gravity }\end{array}$ & $2,5084 \mathrm{gr} / \mathrm{cm}^{3}$ & - & - \\
\hline $\begin{array}{l}\text { Bulk Specific } \\
\text { SSD }\end{array}$ & $2,5610 \mathrm{gr} / \mathrm{cm}^{3}$ & $2,5-2,7 \mathrm{gr} / \mathrm{cm}^{3}$ & Memenuhi syarat \\
\hline $\begin{array}{l}\text { Keausan Agre- } \\
\text { gat }\end{array}$ & $26,92 \%$ & $<50 \%$ & Memenuhi syarat \\
\hline
\end{tabular}

Tabel 3. Hasil Pengujian Agregat Halus

\begin{tabular}{lccc}
\hline $\begin{array}{c}\text { Jenis Pen- } \\
\text { gujian }\end{array}$ & Hasil Pengujian & Standar & Kesimpulan \\
\hline $\begin{array}{l}\text { Absorbtion } \\
\begin{array}{l}\text { Appearent Spe- } \\
\text { cific Gravity }\end{array}\end{array}$ & $2,9368 \%$ & - & - \\
\hline $\begin{array}{l}\text { Bulk Specific } \\
\text { Gravity }\end{array}$ & $2,500 \mathrm{gr} / \mathrm{cm}^{3}$ & - & - \\
\hline $\begin{array}{l}\text { Kandungan Zat } \\
\text { Organik }\end{array}$ & Kuning Muda & Kuning Muda & Memenuhi syarat \\
\hline $\begin{array}{l}\text { Kandungan } \\
\text { Lumpur }\end{array}$ & $4,5 \%$ & Maksimal 5\% & Memenuhi syarat \\
\hline $\begin{array}{l}\text { Bulk Specific } \\
S S D\end{array}$ & $2,5484 \mathrm{gr} / \mathrm{cm}^{3}$ & $2,5-2,7 \mathrm{gr} / \mathrm{cm}^{3}$ & Memenuhi syarat \\
\hline
\end{tabular}

Dari hasil pengujian didapat Bulk Specific SSD dari agregat kasar dan halus berturut-turut 2,5084 gr/ cm3 dan 2,5000 gr/cm3. Nilai tersebut telah memenuhi persyaratan SNI 19702008 yaitu 2,5-2,7 gr/cm3. Bulk Specific SSD ini akan digunakan untuk perencanaan rancang campur. Selain Bulk. Specific SSD, parameter lainnya pada pengujian agregrat telah memenuhi standar yang ada.

Pengujian fly ash dilaksanakan bertempat di Laboratorium MIPA Terpadu, Fakultas Matematikan dan Ilmu Pengetahuan Alam, Universitas Sebelas Maret untuk mengetahui kandungan kimia yang terdapat di dalam fly ash yang akan dipergunakan sebagai material benda uji yang akan dibuat. Hasil analisis parameter kimia, jumlah kandungan $\mathrm{Al}_{2} \mathrm{O}_{3}+\mathrm{SiO}_{2}+\mathrm{Fe}_{2} \mathrm{O}_{3}$ adalah sebesar $64.17 \%$ dengan kandungan $\mathrm{Al}_{2} \mathrm{O}_{3}$ sebesar $11.29 \%, \mathrm{SiO}_{2}$ sebesar $31.76 \%, \mathrm{Fe}_{2} \mathrm{O}_{3}$ sebesar $21.12 \%$. Sedangkan kadar $\mathrm{SO}_{3}$ sebesar 1.67\% dan $\mathrm{CaO}$ sebesar $15.02 \%$. Sehingga menurut 
ASTM C-618 fly ash yang digunakan termasuk kedalam fly ash kelas C sedangkan menurut CSA A3001 termasuk fly ash tipe $\mathrm{Cl}$

\section{Hasil Pengujian Kuat Tarik Baja}

Pengujian kuat tarik baja dilaksanakan di Laboratorium Material Program Studi Teknik Mesin Fakultas Teknik, Universitas Sebelas Maret Surakarta, dengan menggunakan mesin UTM (Universal Testing Machine) sesuai dengan standar ASTM. Baja yang digunakan merupakan potongan tulangan baja polos yang akan digunakan sebagai tulangan pada sampel kubus untuk pengujian kuat lekat dengan diameter tulangan Ø8 mm dengan panjang $30 \mathrm{~cm}$. Adapun hasil pengujian kuat tarik baja disajikan pada Tabel 4.

Tabel 4. Hasil Pengujian Kuat Tarik Baja Ø $8 \mathrm{~mm}$

\begin{tabular}{|c|c|c|c|c|c|c|}
\hline $\begin{array}{c}\text { Kode } \\
\text { Benda } \\
\text { Uji }\end{array}$ & $\begin{array}{c}\text { Diameter } \\
\text { Baja } \\
(\mathrm{mm})\end{array}$ & $\begin{array}{l}\text { Luas penam- } \\
\text { pang }\left(\mathrm{mm}^{2}\right)\end{array}$ & $\mathrm{P}_{\text {leleh }}(\mathrm{N})$ & $\begin{array}{l}P_{\text {maks }} \\
(\mathrm{N})\end{array}$ & $\begin{array}{l}\text { Kuat } \\
\text { Tarik } \\
\text { Leleh } \\
(\mathrm{MPa})\end{array}$ & $\begin{array}{l}\text { Kuat Tarik } \\
\text { Maksimum } \\
\quad(\mathrm{MPa})\end{array}$ \\
\hline A & 8 & \multirow{2}{*}{28,2743} & 16753,1193 & 22220 & 592,52 & 785,87 \\
\hline B & 8 & & 16674,7977 & 22050 & 589,75 & 779,86 \\
\hline & & Rata-rata & & & 591,14 & 782,87 \\
\hline
\end{tabular}

\section{Mix Design}

Perhitungan rancang campur (mix design) mengacu pada peraturan EFNARC 2002. Rancangan campuran adukan beton dapat dilihat pada Tabel 5 .

Tabel 5. Rekapitulasi Rancangan Campuran Adukan Beton (Mix Design Beton)

\begin{tabular}{ccccccc}
\hline $\begin{array}{c}\text { Kadar } \\
\text { Fly } \boldsymbol{A s h}\end{array}$ & $\begin{array}{c}\text { Agregat } \\
\text { Halus } \\
(\mathbf{K g} / \mathbf{m} 3)\end{array}$ & $\begin{array}{c}\text { Agregat } \\
\text { Kasar } \\
(\mathbf{K g} / \mathbf{m} 3)\end{array}$ & $\begin{array}{c}\text { Semen } \\
\left(\mathbf{K g} / \mathbf{m}^{\mathbf{3}}\right)\end{array}$ & $\begin{array}{c}\boldsymbol{F l y} \boldsymbol{A s h} \\
\left(\mathbf{K g} / \mathbf{m}^{\mathbf{3}}\right)\end{array}$ & $\begin{array}{c}\text { Superplasticizer } \\
\left(\mathbf{l t} / \mathbf{m}^{\mathbf{3}}\right)\end{array}$ & $\begin{array}{c}\text { Air } \\
\left(\mathbf{l t} / \mathbf{m}^{\mathbf{3}}\right)\end{array}$ \\
\hline $50 \%$ & 870,30 & 773,70 & 250 & 250 & 8 & 145,00 \\
\hline $60 \%$ & 877,62 & 781,32 & 200 & 300 & 8 & 145,00 \\
\hline $\mathrm{NC}$ & 670,31 & 954,69 & 450 & 0 & 0 & 220,00 \\
\hline
\end{tabular}

\section{Hasil Pengujian Beton Segar}

Hasil pengujian beton segar pada penelitian ini dapat dilihat pada Tabel 6-8.

Tabel 6. Hasil Pengujian Slump Flow

\begin{tabular}{|c|c|c|c|c|c|c|c|}
\hline \multirow{3}{*}{ Kode } & \multicolumn{4}{|c|}{ Flow Table Test } & \multirow{2}{*}{\multicolumn{3}{|c|}{$\begin{array}{c}\text { Syarat menurut } \\
\text { EFNARC }\end{array}$}} \\
\hline & \multicolumn{3}{|c|}{ Diameter } & \multirow{2}{*}{$\begin{array}{c}\text { Waktu } \\
\text { t }_{50} \\
\text { (dt) }\end{array}$} & & & \\
\hline & $\begin{array}{c}\mathrm{d} 1 \\
(\mathrm{~mm})\end{array}$ & $\begin{array}{c}\mathrm{d} 2 \\
(\mathrm{~mm})\end{array}$ & $\begin{array}{c}d_{\text {rata-rata }} \\
(\mathrm{mm})\end{array}$ & & $\begin{array}{l}T_{50} \\
\text { (s) }\end{array}$ & $\begin{array}{c}d_{\text {rata-rata }} \\
(\mathrm{mm})\end{array}$ & Keterangan \\
\hline HVFA 50\% & 700 & 700 & 700 & 3,16 & $2-5$ & $650-800$ & $\mathrm{~V}$ \\
\hline HVFA $60 \%$ & 700 & 700 & 700 & 3,11 & $2-5$ & $650-800$ & $\mathrm{~V}$ \\
\hline
\end{tabular}

Keterangan : $\mathrm{V}=$ memenuhi syarat

Tabel 7. Hasil Pengujian $V$-funnel

\begin{tabular}{cccc}
\hline Kode & T (dt) & $\begin{array}{c}\text { Syarat } \\
(\mathbf{d t})\end{array}$ & Keterangan \\
\hline HVFA 50\% & 9,34 & $8-12 \mathrm{dt}$ & $\mathrm{V}$ \\
\hline HVFA $60 \%$ & 9,57 & $8-12 \mathrm{dt}$ & $\mathrm{V}$ \\
\hline
\end{tabular}

Keterangan : $\mathrm{V}=$ memenuhi syarat

Tabel 8. Hasil Pengujian L-box

\begin{tabular}{cccccc}
\hline \multirow{2}{*}{ Kode } & \multicolumn{5}{c}{ L-Box Type } \\
\cline { 2 - 6 } & $\begin{array}{c}\mathbf{h}_{1} \\
(\mathbf{m m})\end{array}$ & $\begin{array}{c}\mathbf{h}_{\mathbf{2}} \\
(\mathbf{m m})\end{array}$ & $\mathbf{h}_{\mathbf{2}} / \mathbf{h}_{\mathbf{1}}$ & $\begin{array}{c}\text { Syarat } \\
\left(\mathbf{h}_{2} / \mathbf{h}_{\mathbf{1}}\right)\end{array}$ & Keterangan \\
\hline $\begin{array}{c}\text { HVFA } \\
50 \%\end{array}$ & 90 & 85 & 0,9444 & $0,8-1,0$ & $\mathrm{~V}$ \\
\hline
\end{tabular}




\begin{tabular}{cccccc}
\hline $\begin{array}{c}\text { HVFA } \\
60 \%\end{array}$ & 90 & 85 & 0,9444 & $0,8-1,0$ & $\mathrm{~V}$ \\
\hline
\end{tabular}

Keterangan $: \mathrm{V}=$ memenuhi syarat

Nilai slump yang didapat pada pengujian beton normal adalah 10,5 cm. Berdasarkan PBI 1971 nilai slump yang disyaratkan untuk beton normal adalah 7,5-15 cm. Maka nilai slump dari beton normal memenuhi syarat.

\section{Hasil Pengujian Berat Volume}

Berat volume beton bergantung pada berat volume bahan penyusun beton tersebut. Menurut SNI 03-1969-2008 persamaan berat jenis dapat ditunjukan sebagai berikut:

$$
\text { yconc } \quad=\frac{\mathrm{W} \text { (Berat) }}{\mathrm{V} \text { (Volume })}
$$

$$
\begin{array}{lll}
\text { dengan } \quad: & \\
\text { fconc } & =\text { Berat volume beton } & \left(\mathrm{kg} / \mathrm{m}^{3}\right) \\
W \quad=\text { Berat atau massa } & (\mathrm{kg}) \\
V \quad=\text { Volume } & \left(\mathrm{m}^{3}\right)
\end{array}
$$

Pengujian berat volume atau berat jenis beton untuk mengetahui berat jenis masing-masing benda uji, hasil pengujian dapat dilihat dalam Tabel 9.

Tabel 9. Hasil Pengujian Hasil Pengujian Berat Volume Beton Rata-Rata

\begin{tabular}{ccccc}
\hline $\begin{array}{c}\text { Nama } \\
\text { Sampel }\end{array}$ & $\begin{array}{c}\text { Volume } \\
\left(\mathbf{c m}^{\mathbf{3}}\right)\end{array}$ & $\begin{array}{c}\text { Berat } \\
\mathbf{( g r )}\end{array}$ & $\begin{array}{c}\text { Berat Volume } \\
\left(\mathbf{g r} / \mathbf{c m}^{3}\right)\end{array}$ & $\begin{array}{c}\text { Berat Volume } \\
\mathbf{( k g / \mathbf { m } ^ { 3 } )}\end{array}$ \\
\hline KL $50 \%$ & 3442,8000 & 8218,5 & 2,3872 & 2387,1558 \\
\hline KL $60 \%$ & 3397,5000 & 7878 & 2,3188 & 2318,7638 \\
\hline KL NC & 3375,0000 & 7936,5 & 2,3515 & 2351,5556 \\
\hline
\end{tabular}

\section{Hasil Pengujian Kuat Tekan Beton}

Pengujian kuat tekan beton menggunakan sampel silinder diameter $15 \mathrm{~cm}$ dan tinggi $30 \mathrm{~cm}$ yang dilakukan pada beton umur 28 hari dengan menggunakan UTM (Universal Testing Machine). Hasil pengujian kuat tekan beton tersebut disajikan dalam Tabel 10. sebagai berikut:

Tabel 10. Hasil Pengujian Kuat Tekan Beton Rata-Rata

$$
\text { Benda Uji Kuat Desak (MPa) }
$$

\begin{tabular}{cc}
\hline HVFA-1 50\% & 30,27 \\
\hline HVFA-1 $60 \%$ & 29,23 \\
\hline NC-1 & 32,24 \\
\hline
\end{tabular}

\section{Hasil Pembacaan Dial Gauge dan Universal Testing Machine (UTM) pada Uji Kuat Lekat}

Berdasarkan hasil pembacaan dial gauges dan UTM didapatkan grafik hubungan load-displacement rata-rata pada sampel beton HVFA-SCC dengan kadar fly ash 50\%, 60\% dan beton normal dapat dilihat pada Gambar 1.

GRAFIK LOAD-DISPLACEMENT RATA-RATA BETON HVFA-SCC KADAR FLY ASH 50\%, 60\%, DAN BETON NORMAL

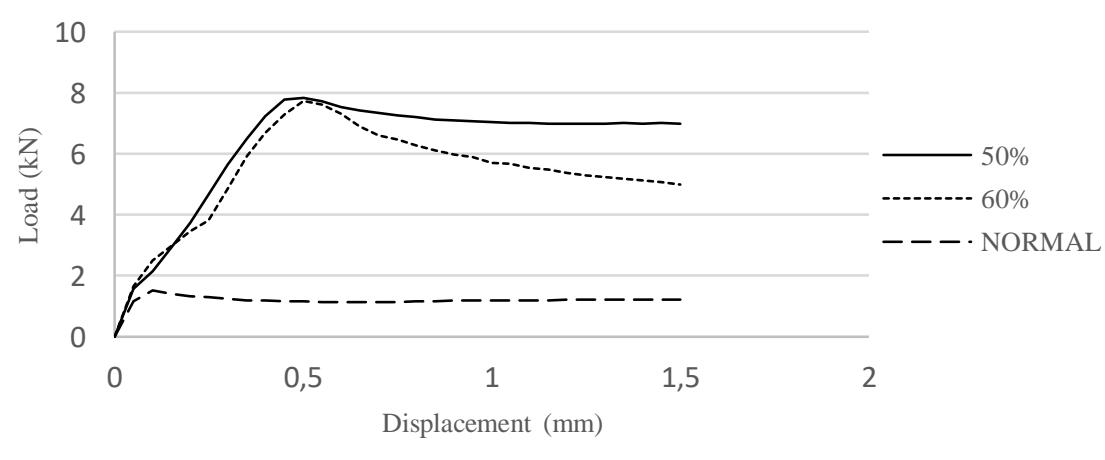


Gambar 1. Grafik Load-Displacement Rata-Rata pada Sampel Beton HVFA-SCC dengan Kadar Fly Ash 50\%, 60\% dan Beton Normal

Berdasarkan hasil pembacaan dial gauges dan UTM didapatkan diperoleh data rekapitulasi hasil pengujian berupa besarnya load pada saat terjadi displacement (slip) $0,25 \mathrm{~mm}$, besarnya load maksimum yang terjadi selama pengujian untuk masing-masing sampel hasil uji dan besarnya displacement saat terjadi load maksimum yang dapat dilihat pada Tabel 11.

Tabel 11. Hasil Pengujian Load Maksimal (Pmaks)

\begin{tabular}{cccc}
\hline Benda Uji & Pmaks $(\mathrm{kN})$ & $\mathrm{P}_{0,25}(\mathrm{kN})$ & $\begin{array}{c}\text { Displacement } \\
\text { saat Pmaks } \\
(\mathrm{mm})\end{array}$ \\
\hline HVFA-SCC 50\% & 7,87 & 4,65 & 0,50 \\
\hline HVFA-SCC 60\% & 7,79 & 3,80 & 0,50 \\
\hline Beton Normal & 1,54 & 1,29 & 0,10 \\
\hline
\end{tabular}

\section{Hasil Perhitungan Kuat Lekat}

Hasil pengujian besarnya kuat lekat beton pada sampel kubus HVFA-SCC kadar fly ash 50\%, 60\% serta beton normal dapat dilihat pada Tabel 12.

Tabel 12. Hasil Pengujian Kuat Lekat Beton

\begin{tabular}{ccc}
\hline No. & Nama Benda Uji & $\begin{array}{c}\text { Kuat Lekat Rata-Rata } \\
(\tau) \\
(\mathrm{MPa})\end{array}$ \\
\hline 1 & KL-HVFA-SCC 50\% & 2,4659 \\
\hline 2 & KL-HVFA-SCC 60\% & 2,0151 \\
\hline 3 & KL-Beton Normal & 0,6841 \\
\hline
\end{tabular}

\section{Tipe Keruntuhan Benda Uji}

Pola keruntuhan pada penelitian ini juga memiliki kesamaan dengan pola keruntuhan pada penelitian yang telah dilakukan oleh Nuroji (2004) pada penggunaan tulangan polos yaitu terjadinya pull out failure.

\section{SIMPULAN}

Berdasarkan hasil pengujian dan analisis yang dilakukan mengenai kajian uji kuat lekat pada beton High Volume Fly Ash Self Compacting Concrete (HVFA-SCC) dengan kadar fly ash 50\% dan 60\% yang kemudian dibandingkan dengan beton normal, dapat diambil kesimpulan sebagai berikut:

a) Dari hasil pengujian, didapatkan nilai gaya cabut (load) dan displacement maksimal pada beton HVFA-SCC kadar fly ash 50\% dan kadar fly ash 60\% lebih besar dibandingkan load serta displacement pada beton normal.

b) Dari hasil pengujian pull out, nilai kuat lekat pada sampel beton HVFA-SCC kadar 50\% lebih besar 3,2822 kali dibandingkan besarnya kuat lekat pada sampel beton normal sebesar. Sedangkan untuk sampel beton HVFASCC kadar fly ash 60\% nilai kuat lekatnya lebih besar 3,0492 kali dari kuat lekat pada beton normal.

c) Tipe keruntuhan benda uji yang terjadi pada penelitian ini adalah tipe pull out failure yaitu terjadinya slip tanpa adanya retak pada beton.

\section{REKOMENDASI}

Untuk menindaklanjuti penelitian ini, perlu dilakukan beberapa koreksi agar penelitian selanjutnya dapat lebih baik. Adapun saran-saran untuk penelitian selanjutnya yaitu: 
a) Untuk mencapai tujuan penelitian yang lebih akurat, disarankan pada penelitian selanjutnya untuk menambah jumlah benda uji sehingga data yang diperoleh lebih akurat.

b) Perlu diadakan penelitian lanjutan untuk mengetahui kuat lekat yang terjadi menggunakan diameter, perbedaan penggunaan jenis tulangan dan panjang tulangan tertanam yang berbeda

c) Perlu meningkatkan metode uji kuat lekat yang lebih efektif menggunakan mesin UTM untuk data yang lebih akurat.

\section{REFERENSI}

Nur'arina Ardini. 2018." The Study Of Split Tensile Strength And Bond Strength On High Strength Self Compacting Concrete With Metakaolin Composition Variation ”. Universitas Sebelas Maret.

Campion, Michael J dan Philippe Josh. 2000. "Self Compacting Concrete Expanding the Possibilities of Concrete Design and Placement", Concrete International April 31-34.

Davidovits k. 1994b. "Properties of Geopolymer Cements", Proceeding First International Conference on Alkaline Cements and Concrete, Scientific Research Institute on Binders And Materials". Kiev state technical university, kiev, ukraina, hal 131-149.

Elagroudy, H. 2003. "Bond Characteristics Of Micro-Composite Multistructural Formable Steel Used In Reinforced Concrete Structures, Master of Science Thesis, Civil Engineering”.North Carolina State University, USA.

Ekaputri,J.J., Triwulan, Priadana, K.A., Susanto, T.E., Junaedi, S. 2013. "Pshyco-Chemical Characterization of Fly Ash", Advanced in Structural Engineering and Mechanics, Jeju, Korea.

Evrianti Syntia Dewi. 2017." The Influence of Reinforcement Bar Diameter on Bond Strenth of Geopolimer Concrete ". Institut Teknologi Sepuluh Nopember.

Andreas Nur Hadi. 2017."The Effect of Fly Ash Content for Stress-Strain Behavior of High Volume Fly ash - Self Compacting Concrete (HVFA-SCC)". Universitas Sebelas Maret.

Sarker, Prabir 2010. "Bond Strength of Geopolymer and Cement Concretes". Advances in Science Technology. 69. Pp 143-151.

Selby, Robert D. (2011), "An Investigation Into the Bond of Steel Reinforcement in Geopolymer and Ordinary Portland Cement Concrete", ZEIT 4500 Civil Engineering: Project, Thesis and Seminar of the Bachelor of Engineering Degree in Civil Engineering, The University of New South Wales. 